\title{
MODOS DE EXISTENCIA Y MODOS DE PROYECTO
}

\author{
Roberto FERnÁNdez \\ CAEAU. Universidad Abierta Interamericana \\ https://dx.doi.org/10.12795/astragalo.2017.i23.08
}

No es nuevo pero todavía puede resultar fructífero plantearse la cuestión de posibles descripciones de la cultura arquitectónica enfocadas como epifenómenos de aquellas taxonomías formuladas en torno de la producción de obras de arte, sobre todo considerando el enfoque adorniano del arte moderno inorgánico desarrollado como resistencia y crítica frente a la omnipresencia de la categoría de la mercancía.

Esta postura adorniana para calificar una de las características de lo que llamará arte inorgánico (siendo el pasaje del arte orgánico al inorgánico un atributo central de la modernidad según Adorno) perfila este devenir más orientado al logro de efectos culturales que a incursiones de mejoramiento de las necesidades sociales que ahora atribuimos a cierto perfil de la arquitectura actual (superada la vertiente cultural-frívola de lo posmoderno) y también creo que consigue distinguir una cualidad po- lítico-cultural, que Adorno atribuye más como intención que como resultado, al programa del arte inorgánico moderno que es ese fugar de la condición de mercancía que pretende (y a menudo no lo consigue) la obra de arte moderna: ese rasgo determinante de lo programático-moderno establecido por Adorno implicará en relación a una supuesta dominancia arte-arquitectura que ésta se ubique en una esfera cuya voluntad de promoción de impacto cultural se distinga de una pertenencia a la condición de mercancía, lo que dejaría fuera de nuestra caracterización toda aquella arquitectura concebida al servicio de imperativos de mercado.

En todo caso y volviendo al esquema de la comprobación de influencias estético-simbólicas, crítico-programáticas y de procedimientos del arte respecto de la arquitectura así como hubieron momentos en que la historiografía crítica moderna se propuso establecer circuitos 
de relaciones entre manifestaciones artísticas y arquitectónicas -por ejemplo en el caso del futurismo, el movimiento De Stijl, la Nueva Objetividad, el cubismo-purismo, el constructivismo, etc.- hoy cabe reinstalar criterios que permitan examinar si no la realidad, la posibilidad de nuevos circuitos, no sólo lingüísticos sino más bien programáticos y teóricos entre formulaciones del arte contemporáneo y la arquitectura para lo cual se pueden utilizar como referencia los estudios de Hal Foster ${ }^{1}$.

En este sentido destaca la importancia que adquieren las posibles relaciones artearquitectura, ahora no ya en relación a algunas características sobre todo lingüísticas de expresiones del arte moderno en su fase de abstracción sino más bien en relación a la influencia de formas de arte contemporáneo que adscriben a posturas de arte conceptual (en rigor, el arte posmimético pero a la vez, pos-objetual que inaugura e instaura Marcel Duchamp) y a propuestas y procedimientos que eliminan el arte de objetos a favor del arte de procesos y situaciones cuyo efecto en la arquitectura orientada a pretensiones de impacto cultural estaría ahora procesándose.

Dentro de las preceptivas adornianas pero también acogiendo el esquema iluminista de la summa kantiana de saberes y críticas y su

1 Por ejemplo, dentro de sus múltiples trabajos, El retorno de lo real. La vanguardia a finales de siglo, Akal, Madrid, 2001 (en que trata una argumentación que partiendo del esencialismo minimalista propone un retorno de realidad para el arte conceptual, como una instancia ulterior y crítica del postmodern en que emerge la figura del artista como etnógrafo) o su Diseño y Delito y otras diatribas, Akal, Madrid, 2004 (en que practica incursiones en las relaciones arte-arquitectura, primero constatando el omni-diseño de la vida tardocapitalista contemporánea que es un conjunto de prácticas derivadas del tecnopoder y ajenas al saber de los designers y luego examinando el impacto cultural de cierta arquitectura como la de Gehry o Koolhaas). entronque con una posible aunque incompleta estética marxista es preciso asumir a la cultura como campo relativamente a-funcional y sus objetos como instituidos por la categoría de la in-utilidad.

Esta definición que configura un campo unificado del arte, sus procedimientos y sus producciones (y también la posibilidad del juicio universal kantiano como tentativa de acceder a una suerte de trabajo crítico científico en tanto no-ideológico) estaría considerando el objeto arquitectónico como parte de la superestructura cultural y desde tal punto de vista, el arribo a un estadio de posible finalización de la idea moderna de proyecto como anticipo calculado de realidad.

Lo que llevaría a considerar que el resultado de aquella noción de proyecto sería la de configurar objetos que re-presentan, más que $o b$ jetos que presentan o productos; objetos más del orden del discurso que de la función-utilidadintercambio. Objetos que por tanto encuentran autonomía respecto de una finalidad práctica (que desinvestiría la valencia cultural propuesta) y que adquieren una resonancia o reverberancia en la esfera específica de lo cultural, aunque de una cultura que al modo gramsciano, pueda resultar potente para cuestionar aspectos de la vida social y proponer alternativas.

Lo que no quiere decir que en tales objetos in-útiles no haya economía (de producción y consumo) ni mercado (como dimensión del intercambio de productores y consumidores, con sus mediaciones) lo que confluye además con derivas del modo productivo capitalista en su advenimiento a una etapa desmaterializada de lo terciario y del predominio del intercambio de bienes simbólicos.

En este aspecto propondríamos analizar las descripciones de nuevas condiciones de 
existencia en la escena tardocapitalista tales como las provistas por Toni Negri, Paolo Virno, Maurizio Lazzarato y Bifo que en cierta forma extienden y potencian el discurso gramsciano fijando el espacio de la hegemonía no ya en la instancia de la producción de bienes útiles (industriales, transables, susceptibles de generar renta y acumulación diferenciales, etc.) ni de sus relaciones y condiciones de producción (en cuanto a la apropiación del plusvalor engendrado en la aplicación de trabajo sobre insumos o recursos de naturaleza) sino en la producción y apropiación de emergentes de algo que empieza a llamarse semiocapitalismo o capitalismo cognitivo. Este nuevo escenario emergente de un desarrollo del capitalismo presenta en sus características y procesos, la obligación de repensar como pueden insertarse en el mismo, los saberes y las prácticas de la arquitectura.

Y profundizando el análisis de las relaciones (con sus posibles dominancias) arte-arquitectura, en particular dentro de las corrientes de pensamiento mencionadas puede ser útil analizar las propuestas de Brian Holmes $^{2}$ que deberían abordarse como vía para interpretar nuevas relaciones entre pensamiento crítico-artístico y formas socio-culturales emergentes de la globalización desigual.

A modo de itinerario descriptivo del recorrido de la arquitectura de un énfasis social-

\footnotetext{
2 Brian Holmes es un crítico-activista norteamericano cuyos trabajos más conocidos (La personalidad flexible, La personalidad potencial) pueden encontrarse con acceso libre en su página brianholmes.wordpress.com. Allí puede accederse al libro Escape the overcode. Activist art in the control society, impreso por Van Abbemuseum en 2009, que contiene una antología de sus trabajos de articulación entre crítica de arte y activismo social, incluso algunos estudios sobre Argentina (como Escalas de vida -sobre el proyecto Toba, Rosario- u Otra pampa es posible -donde registra un diagnóstico crítico sobre procesos agroproductivos argentinos-).
}

moderno a uno cultural-posmoderno (con sus diferentes alternativas: habrá por lo menos una cultura alta de hiperconsumo y frivolidad así como de apogeo del intercambio semiomercantil y unas culturas bajas o microculturas antisistémicas de crítica y resistencia) y de la hipótesis sobre como el devenir del arte de lo abstracto a lo conceptual influye sobre este cambio de énfasis de la arquitectura, me propongo explorar la noción de modo de proyecto.

Un modo es una manera de explicación de una acción proyectual más allá de su mera o automática producción, es decir una manera de descubrir criterios conceptuales de la proposición de proyecto. Dicho de otra forma, un modo de proyecto equivale a la formulación de un producto de la sub-cultura arquitectónica con cierta resonancia frente a rasgos selectivos de estados de cultura frente a operaciones proyectuales ligadas al espesamiento de las categorías-lógicas.

Proyectar según modos implicaría asumir un grado de elecciones frente a un menú de opciones emergentes del contexto cultural del proyectista; proyectar según lógicas ${ }^{3}$ supondría encuadrarse en una de las varias configuraciones en que habrían derivado algunas elaboraciones sintomáticas de la cultura finisecular postmoderna (deconstructivismo, fenomenologismo, etc.).

En este sentido la adscripción a lógicas de proyecto sería en cierta forma, un encuadramiento en las vertientes de la cultura globalizada, mientras que el ejercicio de modos de proyecto significaría antes bien, una opción

3 Hago alusión a la noción de lógicas de proyecto que desarrollé en el par de libros El proyecto final, Dos Puntos, Montevideo, 2000 y Lógicas del proyecto, Concentra, Buenos Aires, 2007. 
singular, determinista y localizada y por tanto, una asunción pragmática de un aquí-y-ahora que sin embargo reivindica un estatus de operación cultural más allá de la pura empiria de una suerte de problem-solving dirimido mediante una acción proyectual.

Podría entonces hablarse de una dialéctica entre high culture de dirección global/local y renovada voluntad cosmopolita (las lógicas) y microculturas locales, de eficacias empíricas pero también de vocación reelaboradora de lo tradicional sin el aparato de los procedimientos de vanguardia (los modos)?

En este punto quizá valga la pena asociar esa eficacia empírica recién mencionada con la recuperación diría, de una voluntad aurática del proyecto reencauzada en una via modal que en efecto podría verificarse como un rasgo o cualidad que por una parte pretende recuperar un control actoral del proyecto (en tanto proyecto de autor o de un performer) y por otra restaurar un valor propio de la cosa artística o cultural emergente de tradiciones de artesanato.

El modo sería por tanto menos susceptible de formar parte de cartografías descriptivas de categorías de la cultura contemporánea y más ligado a opciones a cargo de cada actor proyectual con lo que nuevamente volvemos a la escena fenomenologista o antiestructuralista de los procedimientos inductivos (ir a un grado de inserción en un estado de cultura, procesando algunos rasgos) frente a procedimientos deductivos (básicamente aquellos propios de la deconstrucción derridiano-eisenmaniana, el tipologismo rossiano, el multipopulismo venturiano, el estructuralismo ontologista kahniano, el fenomenologismo cínico koolhaasiano, etc.).

Entonces el trabajo analítico cambia de intereses y procedimientos siendo que la meto- dología genealogista o articulada al canon y las influencias -digamos lo referente a las propuestas nietzcheanas y a las sistematizaciones de canon/influencias de Harold Bloom- que traduce e instala cada acto proyectual en una suerte de red conceptual preexistente (las lógicas) queda por así decirlo bloqueado o clausurado y la noción de modo ya no produce efectos cartográficos sino inductivamente, un desmontaje de las opciones singulares que cada actor proyectual escogió a la hora de construir su discurso proyectual.

Podría asociarse esta alternativa a un concepto semejante a la idea deleuziana de clíni$c a$, incluso en el sentido que éste le dio asociando el trabajo de la crítica al trabajo singularizado del análisis freudiano-lacaniano, para el cuál es cierto que existen como sombra o escenario distante una cierta tipología genérica de figuras del malestar psíquico (neurosis, esquizofrenia, etc.) pero que el análisis del caso singular no trabaja en una mera deconstrucción deductiva sino que a lo sumo, acumula y comprueba en una sumatoria clínica, de forma que los análisis puntuales (en nuestra asociación, los proyectos modales) refieren o establecen la relación entre caso y tipo, pero la cura del caso -o sea el análisis propiamente dicho- converge a una relación entre análisis (o crítica) y clínica en la que ésta emerge como un productivo y progresivo campo de permanente y continua redefinición del tipo originario de enfermedad.

El modo refiere -a veces a través de una interpretación o un análisis crítico, no necesariamente como consecuencia de la transparencia metódica del procedimiento del proyectista- a una determinada evidencia en la búsqueda de efectos culturales, resonancias o impactos en el estado de cultura en que ope- 
ra el proyectista y/o calculadas intenciones de hacer parte de sub-culturas arquitectónicas. La crítica, basada u orientada a descubrir el modo del proyecto considerado, adquiere entonces también una condición singular, homóloga si se quiere a la singularidad del proyecto analizado.

Quizá además valga la pena señalar que la crítica modal que se estaría postulando es más precisamente un análisis modal o sea un trabajo diseminativo e interpretativo del modo de proyecto en cuestión que suspende el aspecto axiológico de la crítica, sobre todo la crítica en el sentido kantiano ligada a la formulación de juicios universales. Pasar de la crítica al análisis significa conocer los porqués de un hecho proyectual, no valorar o evaluar su performance.

Probablemente la época admite o hasta exige más estas singularidades casi en sintonía con el criterio que antes reconocimos en el análisis lacaniano, de una manera en que los juicios de valor o las construcciones interpretativas plurales aparezcan no como aprioris sino como deducciones eventualmente emergentes de una crítica entendible como clínica.

A partir de estas consideraciones acerca de valorar la singularidad del modo cabe postular la existencia de relaciones posibles entre modo y moda o modalidad, entendible como aplicación sistémica de variables generalesepocales de gusto y contrariamente, efectos de resistencia a fenómenos estéticos generalizados derivados de cuestiones en general ligadas a la tradición. Por ejemplo los elementos de hibridación y mestizaje en la estética americana o las resistencias expresivas a los discursos tecno-comunicacionales minimalistas derivados de las tradiciones barrocas y simbolistas.

El tema de la moda como disposición táctica del gusto de época asociado en general a propósitos ideológicos y económicos (en tanto predisposición de cierto estado de consumo) se acerca a la esfera de lo cotidiano que es uno de los polos que Holmes señala como tarea de la crítica, planteando que ésta trate de establecer las relaciones entre el estado político del mundo y tales circunstancias de la vida cotidiana colectiva, estrategia analítica que en otro orden, ocupó buena parte de los intereses frankfurtianos sobre todo de la etapa que Adorno dedicará al análisis de la cultura de masas o en muchos estudios del ahora revalorado Sigfried Kracauer ${ }^{4}$.

Esta ampliación del análisis crítico de los productos culturales -que en la arquitectura reciente advienen a propósito principal de su cometido histórico- a dimensiones singularizadas del proyecto se abre en la línea de las propuestas finales de Frankfurt, a indagar sobre temas como la persuasión o la alienación es decir, dimensiones operativas de los discursos de las modas y confluyen a delinear una de las dos críticas que proponen Boltanski y Chiapello en su célebre estudio sobre el capitalismo ${ }^{5}$.

4 Hay muchas antologías recientes de los trabajos críticos de Kracauer como Estética sin territorio, edición armada por Vicente Jarque, COAATM, Murcia, 2006. En relación a la importancia histórica de la relación entre estéticas y aspectos de la cultura cotidiana popular destaca el ensayo allí incluido El ornamento de la masa (que arranca con la frase: El lugar que una época ocupa en el proceso histórico se determina con mas fuerza a partir del análisis de sus manifestaciones superficiales e insignificantes que a partir de los juicios de la época sobre sí misma) o los estudios sobre los efectos psicológicos en capas sociales bajas de nuevos medios como el cine (Las pequeñas dependientes van al cine) o los cambios en la disposición perceptiva del público común (Publicidad luminosa).

5 Boltanski, L.- Chiapello, E., El nuevo espíritu del capitalismo, Akal, Madrid, 1999. En este volumen se formula una versión del capitalismo como forma final de la historia en tanto se considera el primer estadio socio-cultural cuya compulsión acumulativa lo lleva a integrar y absorber-procesar toda crítica anterior frente a la cuál caben dos grandes 
El modo si se quiere implica cierta conciencia de textualidad en tanto voluntad de discursividad proyectual que supone a la vez una doble explicitación, en el objeto-proyecto, de un armado codificador (o una sintaxis de elementos arquitecturales) y un armado referencial o sea cierta estructuración de un conjunto texto/contexto.

Lo referencial suplementa al objeto empírico, la búsqueda de alguna repercusión o efectuación en aquella dimensión que nombramos estado de cultura y a veces también supone una concienciación del proyectista en cuanto pensar su producto como parte de la sub-cultura arquitectónica. La voluntad discursiva no necesariamente se articula con un estatuto de racionalidad sino incluso de requisitos discursivos para efectuar su crítica o negación.

La idea de un suplemento textual del proyecto tiende a fundar su condición más allá de una previsible consumación de un fait accompli que genéricamente explota el costado caprichoso o lúdico de cierta noción de arte como pura manifestación empírica de destreza o genialidad. Va mas allá de los automatismos gestualistas y asimismo deniega las fundamentaciones referenciales frívolas o inconsecuentes.

La textualidad -aún aquella suplementada o producida ex post- se manifestaría entonces no como un agregado de proyecto sino como la parte de éste que alega un intento de espesamiento y complejización de la pura empiria re-

actitudes tipológicas de crítica: la que llaman crítica social (que es una crítica de la explotación) y la que definen crítica artista (que es una crítica de la alienación).

En una línea similar pero mas pesimista, Eduardo Subirats en su libro Las estrategias del espectáculo. Tres ensayos sobre estética y teoría crítica, Cendeac, Murcia, 2005, plantea que tal compulsión capitalista conduce a un grado superior de desarrollo y alienación en tanto el capitalismo actual alcanza la paradoja de consumir el espectáculo de su propia destrucción. petitiva o la pretensión de exhibir el resultado de la acción proyectual como un mas allá de una mera performance, acting o puesta en escena.

Los suplementos de textualidad como operación de sentido y parte constitutiva de la dimensión cognitiva del proyecto pueden también darse sobre las prácticas manu-factas y el imperio de lo artesanal manteniendo su entidad de actuación o manipulación sobre unas materias primas pero denegando un posible automatismo irreflexivo e infinito en su repetición: a veces lo textual-discursivo aplicado a un procedimiento artesanal remite a indagar su genealogía o considerar su teleología, es decir reflexionar sobre el origen o la finitud de aquel procedimiento. Es decir, historizarlo o temporalizarlo lo que equivale a cuestionar el aspecto ontológico de lo manu-facto.

En este sentido el concepto de modo aplicado a esta clase de producción dominada por estrategias repetitivas y fundadas en destrezas replicantes, opera como cierta intelectualización relativa del procedimiento artesanal, forma de deconstruir aquella aparente reproducción automatista.

De tal manera operando como una maniobra sustractiva de una serialidad infinita, el modo concebido como suplemento discursivo apunta a una utilización fragmentaria de lo artesanal tal que despojado de su pura empiria puede representarse en un plan de discursividad mas abarcativo a veces de tipo político-ideológico.

Podría ahora profundizarse una hipótesis a saber, que el armado codificador o la sintaxis mencionada tributa en modo superlativo a la codificación de la modernidad. Pudiera así presentarse la dicotomía entre armado codificador moderno y armado referencial posmoderno o 
pos-posmoderno; texto moderno/contexto posmoderno-pos-posmoderno.

En la contratapa de un libro de Nicolas Bourriaud $^{6}$ dice lo siguiente: La tarea histórica del siglo XXI es rescribir la modernidad. No para hacer tabula rasa o buscar prestigio en el depósito de la historia sino para inventariar y seleccionar, para usar y "descargar archivos".

Tal proceso de rescritura coincide con lo que señalamos como suplementación discursiva inédita aplicada sobre codificaciones modernas ya instituidas, conocidas y manipuladas.

Desde esa perspectiva lo moderno aparece o se restituye (como un fuera de la historia) como lenguaje o materia prima del armado codificador, pero lo posmoderno es el campo referencial que abarcaría el conjunto de esas operaciones, incluso aquellas de total desinvestimiento de los contenidos político-ideológicos modernos: o sea que lo posmoderno constituye un paisaje referencial de rescrituras modernas tendenciadas por una voluntad cínica de reducción a una proyectualidad basada en manejos frívolos de significantes.

Desde otro punto de vista lo moderno se visualiza fuera de la potencia figurativa de sus propuestas lingüísticas, como una formulación epocal cuya historicidad es precisa tanto como su pasaje a una instancia de desactualización en aras de formaciones ulteriores que otorgan al pensum proyectual categorías innovativas que en tanto tal intentan criticar

\begin{tabular}{l|l|l|l}
\hline Categoría & MODERNO & $\begin{array}{l}\text { POSMODERNO } \\
\text { DECONSTRUCCIONISTA }\end{array}$ & $\begin{array}{l}\text { POSMODERNO } \\
\text { ECOLOGISTA }\end{array}$ \\
\hline Meta-narrativa & Salvación\&Progreso & Ninguna & Regresión cosmológica \\
\hline Noción de verdad & Objetivista & Extrema & Experimental \\
\hline Mundo & Colección de objetos & Agregado de fragmentos & Comunidad de sujetos \\
\hline Realidad & Orden fijo & Construcción social & Fragmentada \\
\hline Autoconciencia & Ingeniería social & Fragmentada & Procesual \\
\hline Verdad primaria & Lo universal & Lo particular & Lo particular en contexto \\
\hline Fundamento & Universo mecanicista & Ninguno (no fundamento) & Procesos cosmológicos \\
\hline Naturaleza & N como oposición & N como objeto equívoco & N como sujeto \\
\hline Cuerpo & Control del cuerpo & Descripción del cuerpo & Confianza en el cuerpo \\
\hline Ciencia & Reduccionista & Solo una narrativa & Complejidad \\
\hline Economía & Corporativa & Poscapitalista & Comunitarista \\
\hline Foco político & Estado-Nación & Lo local & Comunidad de comunidades... \\
\hline Sentido de lo divino & Dios Padre & Gestualidad pro-sublime & Creatividad cósmica \\
\hline Metáforas clave & Mecánica y Ley & Economia Libidinal & Ecología \\
\hline
\end{tabular}

6 Bourriaud, N., Postproducción. La cultura como escenario: modos en que el arte reprograma el mundo contemporáneo, Adriana Hidalgo, Buenos Aires, 2009 (el texto original francés es de 2003). 
y superar el sustrato ideológico (pero no el operativo) de la modernidad.

Es el caso del análisis de Peter Buchanan que coteja la finitud histórica de lo moderno en base a la consideración de 14 categorías analíticas que comparan tres etapas o momentos: el moderno, el postmoderno deconstruccionista y el postmoderno ecologista ${ }^{7}$, como se sintetiza en el siguiente cuadro.

Fuera de las intenciones un tanto románticas e ingenuas de un devenir de la teoría de la arquitectura aterrizado según Buchanan, en la nobleza de una recuperación del sujeto dentro de la complejidad de lo ambiental y en torno de formaciones socio-políticas comunitaristas (una forma por lo menos optimista sino ingenua de referir a una fase histórica signada por la violenta decadencia capitalista) lo cierto es que esta clase de análisis se concentra en determinar la obsolescencia histórica de una noción de modernidad cuyas características ideológico-políticas resultan claramente situadas en torno de un momento histórico finito y extinto, es decir aquel propio de la organización de las llamadas culturas de las sociedades industriales.

Buchanan evalúa que el declive de una arquitectura moderna mas cercana a la voluntad política de pertenecer al despliegue del proceso de la modernización a favor de un repliegue cultural o para-social debe medirse según el anacrónico compromiso moderno progresista, mecanicista y nacionalista (aunque inserto en

7 Buchanan, P., The Big Rethink. Farewell to Modernism, ensayo en Architectural Rewiew 1380, Febrero 2012, pp. 82-93, Londres, 2012.

El ensayo se completa con un segundo capítulo denominado The Big Rethink. Towards a Complete Architecture, que se inserta en el siguiente número 1381 de $A R$, Marzo 2012, pp.67-81, Londres, 2012. paradigmas universalistas) que se transforma en una etérea llegada a un estado comunitarista de la sociedad que resulta orbital y ajeno al todavía omnipresente imperio del capital.

De manera entonces que existiría así como una per-duración -que es como una larga duración-de lo moderno y ello es así en tanto podamos entender lo moderno como el background cultural del programa general de formación del capitalismo (y la vez su crítica).

El desarrollo largo de lo moderno podría así verse como el proceso cultural que acompaña la modernización que vincula el capitalismo comercial (Renacimiento) con el capitalismo industrial y el imperialismo (siglos XIX y XX) -esa sería una de las tesis historiográficas básicas de Tafuri- y en tal sentido es que se elabora una estructura cultural imbricada con la cuestión del capitalismo a largo plazo y la articulación inevitable de cada producto cultural con un estatuto de mercancía aun con la tensión crítica que le asignó Adorno a esa modernidad cuya cualidad era producir efectos culturales u obras que en primer lugar trataran de fugar casi siempre de manera infructuosa, de su conversión en mercancía.

Así como la historia larga del capitalismo (que atraviesa al menos las fases comercial, industrial e imperialista, incluyendo en cada fase ya desde el comienzo a fines del siglo XV, la dialéctica global o mundial entre centros y periferias) tiene facetas y características evolutivas dentro de su lógica intrínseca y de su sentido mismo de existencia histórica, también la cultura moderna -como aparato suplementado y a veces crítico, al sistema capitalista- tiene facetas y variaciones, tanto en la evolución del lenguaje como en la articulación con el desarrollo de la producción y el consumo o la cuestión inherente de la formación del mundo urbano- 
burgués, aunque también tiene sus límites de potencia crítica o de autonomía socialmente proactiva, que es la irreductible cualidad de mercancía que Tafuri -menos optimista y experimental que Adorno- supo advertir en la arquitectura moderna desplegada entre el siglo XV y nuestra época.

En línea con esa interpretación (que le niega autonomía a la modernidad respecto de la modernización según la ya clásica proposición habermasiana) lo mal llamado pos-moderno pudo así ser interpretado como la reutilización de los materiales modernos en consonancia con la emergencia del semiocapitalismo, que en síntesis es la argumentación central de Fredric Jameson quién incluso le atribuye gran relevancia a ciertas aportaciones de la arquitectura posmoderna como la de Place Bonaventure y Portman a tal asociación entre cultura altomoderna y etapa de un late-capitalism signado por lo inmaterial o la circulación financiera improductiva del capital.

Siendo así, lo posmoderno como fenómeno artístico o lingüístico no supone un desenganche nítido con el lenguaje moderno sino apenas su manipulación en diversas estrategias discursivas o retóricas como la neutralización de las asociaciones entre contenido y continente -o entre función y forma- y la tendencia a restringir el grado de actualidad del discurso moderno para pasar a dotarlo de un aura de historicidad que lo desinvistiera de su supuesta potencia crítica social o política y lo asimilara a material de utilización ecléctica e historicista en modo análogo a las operaciones que la cultura del siglo XIX había perpetrado respecto de los estilos clásicos.

El desdoblamiento que Buchanan propone entre un posmoderno deconstruccionista y un posmoderno ecologista quizá pueda explicarse mejor según cierta secuencialidad entre lo moderno, lo posmoderno y lo pos-posmoderno, si es que lo primero puede entenderse como acople al capitalismo expansivo inclusivo de modelos de welfare y coexistente con la agonía socialista todavía bipolar, lo segundo como manifestación del pasaje a un capitalismo menos industrial y mas semiocapitalismo o cognitive capitalism (pero en modo alguno representativo de una economía poscapitalista como Buchanan define) y lo tercero como eclosión de formas ulteriores a un cierto desastre madurativo del proceso capitalista (desastre verificable en la crisis financiera internacional desatada desde el inicio de la segunda década de este siglo) que fracturan en esquirlas, estructuras como las socio-económicas de clase o las políticas de estado-nación sin que ello signifique reemplazos de formas comunitaristas o pos-societales y menos, triunfo de políticas de corte ecologistas (aunque se agudiza cierta percepción de catástrofe ambiental y de la afluencia o disponibilidad de recursos naturales).

Lo pos-posmoderno implicaría entonces un nuevo proceso de reutilización de materiales modernos ahora dentro de la estrategia general del desarrollo del capitalismo globalizado, tanto en relación a la expresión hegemónica de dicha fase histórica como en cuanto a la emergencia de las fragmentaciones propias de la escena multicultural.

Aludiríamos a un pos de lo posmoderno en tanto inauguración si se quiere, de una fase desprovista de la voluntad repertorista o codificadora de nuevos cánones que tenía el ahora denominable movimiento posmoderno (instituído por ejemplo, en la vocación analítica de Lyotard o Derrida, seducidos por un desemboque 
-posmoderno- en cierta pasión interpretativa y hasta poshermenútica en tanto productiva, después que metodológica y axiológicamente ellos estipulan la homología entre primerostextos productivos y segundos-textos reproductivos, entre texto y con-texto o comentario) había propuesto como organización de la producción de saberes en el alba de la globalización política-económica de los 70 y que nosotros habíamos explorado para la arquitectura de tal época dentro de la noción de lógica de proyecto y de la posibilidad de efectuar una cierta taxonomía de procedimientos discursivo-proyectuales en los que el proyecto era segundo-texto reproductivo de primeros-textos dominantemente provenientes de las filosofías científicas o artísticas (caos, azar, montaje, archivo, etc.).

Lo pos-posmoderno constituye entonces el abandono de esa voluntad taxonómica de los discursos posibles (cuya entidad en buena parte había emergido del reprocesamiento de materiales modernos marcando cierta longue durée histórica de los mismos o más aun su relativa des-historicidad en la oposición neonietzcheana entre lo clásico y lo moderno) y el desemboque en una incertidumbre de disposiciones discusivas que diría que responde por una parte a la trituración de temas y métodos propios del llamado multiculturalismo y por otra a cierta refundación antropológica de una subjetividad paradójicamente inmersa en lo multitudinario (Negri).

Ya sea como declinación de la modernidad de talante cosmopolita-estructuralista o también del modelo de las lógicas posmodernas que asimismo adscriben a formatos axiomáticos que referencian el proyecto a ciertas categorías conceptuales emergentes de propuestas de la filosofía estética o la filosofía científica, surge política e ideológicamente la necesidad del en- foque inductivo-fenomenológico que remite a la escena guattariana de la revolución de las subjetividades, compatible con el posmarxismo de Negri que sitúa el núcleo de la acción política transformadora en las posibles articulaciones de sujetos, redes y multitudes.

La explosión de subjetividades no garantiza nada, tan solo acoplarse a un nuevo espíritu de época, marcado por la ambigüedad y las contradicciones que se resisten a organizarse en modelos de sentido, habida cuenta además de la condición un tanto decadente que adviene con el repliegue de las euforias consumistas y del moderado progresismo del welfare state que la reciente literatura sociológica-política acuerda en llamar impasse.

Sin embargo, debería existir alguna precaución crítica y taxonomista u organizadora del posible festival anarco-modalizante; es decir prestar atención al posible desorden de la mera acumulación, el descentrado o la difuminación de ordenes clasificatorios y aun jerárquicos o dicho de otra forma, renovar la inquietud para encontrar y analizar el derrotero de nuevos form givers y maitres à penser que ya no serán los del medio siglo precedente, pero con cuya capacidad de modelizar los nuevos escenarios de fenómenos subjetivos se debería contar como manual de instrucciones para recorrer esta etapa histórica.

Deberían pués haber mecanismos selectivos de los analistas para el desarrollo acumulativo de una serie interpretativa de modos que pueda derivar en una nueva acumulación de análisis puntuales y nuevas clasificaciones: una de tales tareas, tanto reformuladora de tradicionales operaciones de conceptualizar relaciones entre ideologías y productos culturales cuanto revulsiva en registrar nuevas formas 
de producción cultural es aquella emprendida en las cartografías lógicas desarrolladas en un sentido geopolítico por Fredric Jameson, por ejemplo en sus estudios de cines alternativos ${ }^{8}$.

Lo que emprende Jameson es por una parte, un completamiento de la escena marginal incorporando productos culturales orbitales (y tomándose el trabajo de entenderlos no como réplicas menores o espejamientos primitivos de referencias centrales) y por otra, analizar la densidad de relaciones entre lo global y lo fragmentario (en tanto constelación de diversas localías).

Otro abordaje de pretensión a la vez taxonomista (por cuanto estipula una serie de tipos discursivos) y fragmentarista (en tanto asume la multimodalidad discursiva emergente de una voluntad subjetiva) es el que asume Félix Guattari en el único de sus textos específicamente abocados a la arquitectura ${ }^{9}$.

Guattari remite a la idea desarrollada desde hace varios milenios del desarrollo de caparazones que imitan a los crustáceos y que resultan expresiones ecolíticas de disposiciones sociales en

\footnotetext{
8 Jameson, F., La estética geopolítica. Cine y espacio en el sistema mundial, Paidós, Barcelona, 1995. En el primer párrafo de la Introducción, Jameson explicita su proyecto: Las películas que se comentan aquí han sido seleccionadas con la intención de trazar un mapa o una radiografía no sistemáticos del propio sistema mundial: desde lo que normalmente se entiende por superpoderes, pasando por esa zona tan industrializada de un antiguo Tercer Mundo ahora llamado el Círculo del Pacífico, hasta una confrontación entre el Primer Mundo -o la tecnología europea a su mayor nivel de conciencia (en Godard)y una meditación sobre esta tecnología realizada desde el Tercer Mundo, también a su mayor nivel de conciencia, a la vez que reflexivamene "naif" (en la obra del realizador filipino Kidlat Tahimik). (p.21).
}

9 Se trata de La enunciación arquitectónica, pequeño ensayo que se inserta en la miscelánea aplicativa de nociones desplegadas en el libro Cartografías esquizoanalíticas (Manantial, Buenos Aires, 2000: la edición francesa original es de 1989) del cual forma parte (pp.263-272). procesos que involucran a arquitectos, sastres y comunicadores pero que arriban a un estado de cosas (ejemplificable en la ciudad de México cuyos 40 millones sancionan la imposible acción salvífica de profetas modernos como Corbusier o Haussmann) en que los arquitectos, que Hegel ubicaba en primer lugar, hoy se restringen a cierto dominio de las construcciones suntuosas, degradación solo esquivable con alternativas como la teoría pura, la utopía, la nostalgia de una vuelta al pasado o la contestación crítica, opciones que empero no logran disimular que el objeto de la arquitectura voló en pedazos.

Situación en la cuál re-inventar la arquitectura ya no podría significar relanzar un estilo, una escuela, una teoría con vocación hegemónica, sino recomponer, en las condiciones de hoy, la enunciación arquitectónica y en cierto sentido, el oficio de arquitecto.

De allí que desde el momento en que el arquitecto ya no tendría solamente como objetivo ser un plástico de las formas edificadas sino que se propondría también como un revelador de los deseos virtuales de espacio, lugares, recorridos y territorio, deberá llevar el análisis a las relaciones de corporalidad individuales y colectivas singularizando constantemente su enfoque y deberá volverse además, un intercesor entre estos deseos revelados a si mismos y los intereses que estos contrarían o dicho en otros términos, un artista y un artesano de lo vivido sensible y relacional.

Guattari remite a una necesaria refundación del rol del arquitecto en la necesidad de situarlo en analizar ciertas funciones específicas de subjetivaciones, lo cuál implica según su opinión, en primer lugar, descartar una simple posición de observación crítica y en segundo término, desplazar el acento del objeto al proyecto, dado que cualquiera sea la característica de su 
expresión semiótica y de sus contenidos semánticos, una obra arquitectónica requeriría en adelante, una elaboración específica de su "materia" enunciativa.

Siguiendo con el enfoque de percepciónafección que trabajaron en la última época de su desarrollo filosófico junto a Deleuze, Guattari identifica dos modalidades de consistencia de la enunciación de un concepto arquitectónico, una polifónica del orden del percepto inherente al despliegue de los componentes que contribuyen a la puesta en existencia discursiva y otra, ético-estética del orden del afecto, inherente a su toma de ser no discusiva.

En este punto se podría decir que la dimensión polifónica o discursiva es lógicamente clasificable -o que admite ciertas categorías de actuaciones que quizá se instalen mas en el proceso de enunciar el programa del objeto o situación a producir-mientras que la dimensión ético-estética o no-discursiva sea más del orden de la modalidad subjetiva o afectiva de enunciación y que irrumpe más en la definición del proyecto del objeto o situación.

Aquí quizá encontremos otra teorización de las diferencias entre lógicas y modos en la producción de los hechos de la arquitectura.

En tal dimensión polifónica o discursiva Guattari indica ocho tipos de disposiciones:

- 1 Enunciación geopolítica o posición en el mundo, ambiental, climática, paisajística, gravitatoria en los archipiélagos de ciudad.

- 2 Enunciación urbanística o contexto regulatorio tanto leyes como costumbres e incluso contaminación de modelo e imagen (o escala de vecindad) y por tanto, determinaciones contextualistas del entorno.

- 3 Enunciación económica o forma compleja de establecer un valor mercantil de la cosa en cuestión, incluyendo aspectos como los del prestigio, estatus o figuración social.

- 4 Enunciación funcional o función de equipamiento en razón de la utilización específica de cada cosa, colectivos o privados y articulados en una doble red de relaciones complementarias horizontales o de posición de cada segmento construido en un conjunto de estructuras urbanas hoy interconectadas en el seno del capitalismo mundial y de relaciones de integración verticales que van desde los micro-equipamientos de confort a los macro-equipamientos de infraestructura.

5 Enunciación técnica o toma de palabra del aparataje y mas generalmente de los materiales de construcción.

- 6 Enunciación significante o afectación de la forma edificada (mas allá de los semantemas funcionales) con un contenido significativo compartido por una comunidad humana mas o menos extensa y delimitada de otras comunidades que no comparten tal contenido.

- 7 Enunciación de territorialización existencial de orden tanto perspectiva como etológica y que abarcaría las tipologías espaciales euclidianas, proyectivas y topológicas definiendo al espacio arquitectónico como un operador concreto del metabolismo entre los objetos del afuera y las intensidades del adentro.

- 8 Enunciación escritural o forma de articulación del conjunto de los restantes componentes enunciativos y a la vez 
apertura al despliegue de los aspectos ético-estéticos del objeto edificado.

Como antes mencionamos Guattari piensa en dos conjuntos nocionales que atraviesan el proceso de producción de arquitectura: las enunciaciones objetivas recién descriptas y lo que llama ordenadas ético-estéticas (que comprenden las ordenadas cognitivas o co-ordenadas energéticoespacio-temporales que otorgan lógicas a las conjuntos discursivos articulando los primeros cinco dispositivos enunciativos objetivos arri- das en el trabajo proyectual según mecanismos subjetivos o autorales que asigna a lo que designa como ordenadas cognitivas.

Y luego, como abordaremos un poco mas abajo, toda la puesta en juego de las ordenadas subjetivas (que trituran o licúan la nitidez de las enunciaciones previas) nos permite entender-aunque no definir ni menos clasificar- la cuestión personalizada de los modos de proyecto. Incluso me animo hipotéticamente a presentar un posible cuadro de homologías entre enunciaciones y lógicas:

\begin{tabular}{l|l|l|l|l}
\hline ENUNCIACIÓN & GEOPOLÍTICA & URBANÍSTICA & ECONÓMICA & FUNCIONAL \\
\hline LÓGICA & FENOMENOLÓGICA & CONTEXTUAL & TECNOLÓGICA & ESTRUCTURALISTA \\
\hline ENUNCIACIÓN & TÉCNICA & SIGNIFICANTE & EXISTENCIAL & ESCRITURAL \\
\hline LÓGICA & FORMALISTA & COMUNICACIONAL & TIPOLÓGICA & DECONSTRUCCIONISTA \\
\hline
\end{tabular}

ba puntualizados; las ordenadas axiológicas o de valoración ética, económica y política y las ordenadas estéticas, que determinan los umbrales de acabamiento de una entidad, objeto o un conjunto estructural, en la medida que éstos se ponen a emitir sentido y forma por su cuenta).

En este punto nuevamente creo necesario puntualizar que Guattari describe dos conjuntos operacionales asimilables a mi presentación dual de lógicas y modos.

En efecto, creo que las ocho categorías enunciativas o discursivas objetivas - ordenadas y articuladas en procedimientos subjetivos como indica respecto de lo que define como ordenadas cognitivas, que siendo subjetivas implican una operacionalización de las cinco primeras enunciaciones- propone el sistema que llamé de las lógicas proyectuales, entendibles esencialmente como formaciones discursivas o enunciaciones en el léxico guattariano, utiliza-
En la parte final de su ensayo Guattari trabaja la relación entre sus dos conjuntos objetivo y subjetivo de nociones (que asimilo por mi parte a los conceptos cerrado de lógica y abierto de modo) para proponer que el proyecto en rigor implica un juego entre lo discursivo previo y lo no discusivo ulterior: Tras su cara exterior discursiva, este objeto (el objeto arquitectural, la cosa emergente de un proyecto pero también el proyecto como cosa u objeto) se instaura en la intersección de mil tensiones que lo tironean en todos los sentidos; pero tras sus caras enunciativas ético-estéticas, vuelve a pegarse a un mundo no discursivo cuyo abordaje fenomenológico se nos da a través de la experiencia particular de los afectos espacializados. Mas acá de un umbral de consistencia cognitiva, el objeto arquitectónico bascula hacia lo imaginario, el sueño, el delirio, mientras que mas acá de un umbral de consistencia axiológica, sus dimensiones portadoras de alteridad y deseo se deshacen... y que mas acá de un umbral de consistencia estética cesa 
de enganchar la existencia de las formas y de las intensidades destinadas a habitarlas.

De esta forma Guattari reconoce por así decirlo, un sustrato de lógica sobre la cuál se teje una alteridad o especificidad propia en cada caso del sujeto de proyecto y que se acerca a la fenomenología de lo que entendemos como modal: esa puesta en juego de modos de proyecto, en cada caso únicos y personales, especificaría en último análisis -sigue diciendo Guattari- el arte del arquitecto (y eso sería) su capacidad de aprehender esos afectos de enunciación espacializada. Sólo que es preciso admitir que se trata de objetos paradójicos que no pueden ser delimitados en las coordenadas de la racionalidad ordinaria y que solo podemos abordar indirectamente por meta-modelización, por rodeo estético, por relato mítico o ideológico.

Casi accediendo a admitir una categoría de enigma o misterio propia del objeto arquitectural Guattari indica que la forma arquitectónica no está destinada a funcionar como gestalt cerrada sobre sí misma sino como operador catalítico generando reacciones en cadena en el seno de modos de semiotización que nos hacen salir de nosotros mismos y nos abren campos inéditos de posible.

Subrayamos en el párrafo precedente como aparece la noción de modos (de semiotización o sea, de otorgamiento de sentido a la operación proyectual y a su término u objeto).

Después Guattari ofrece un párrafo de ejemplificación existencial del cual se podría extraer una noción mucho más amplia y compleja del concepto de programa o expectativa o deseo de proyecto, con lo cual nuestro autor pone en el imaginario del sujeto demandador de arquitectura -no del sujeto proveedor o proyectista- una parte sustancial de la razón fundante de alguna clase de acción arquitectural, incluso en tal caso, no necesariamente de una acción proyectual: Es el mismo movimiento de territorialización existencial y toma de conciencia sincrónica que hará "trabajar" juntas cosas tan diferentes como una caja de zapatos y de tesoros, bajo la cama de un niño hospitalizado en un internado médico-psicológico, el ritornelo contraseña que quizá comparta con algunos camaradas, el lugar en el seno de la constelación particular que ocupa en el comedor, un árbol-totem en el patio de recreación y un recorte de cielo conocido sólo por él.

Hasta aquí la configuración por así decirlo sino de una demanda o programa, de un deseo de arquitectura como organización de hechos que posibiliten y potencien esas vivencias: frente a ello, que le compete hacer al proyectista?. Le corresponde al arquitecto -sigue Guattari- si no componer una armónica a partir de todos esos componentes fragmentarios de la subjetivación (del otro sujeto del proyecto, el que requiere actuación o solución proyectual), ipor lo menos no mutilar por adelantado lo esencial de sus virtualidades!

Pero más allá de esa escena de articulación de deseo-proyecto dirá Guattari que:

para recomponer de este modo los territorios existenciales, en el contexto de nuestras sociedades devastadas por los flujos capitalísticos, el arquitecto debería ser capaz de detectar y explotar procesualmente el conjunto de los puntos de singularidades cataliticas susceptibles de encarnarse tanto en las dimensiones sensibles del aparato arquitectónico como en las composiciones formales y las problemáticas institucionales mas complejas. Con el fin de lograrlo todos los métodos cartográficos serán lícitos 
desde el momento en que su compromiso...encontrará su propio régimen de autonomización ético-estética.

Desde el punto de vista de la relación entre proyecto e historia (o mejor, entre modos proyectuales e historia) cabe explorar el comportamiento antivitruviano de los modos de proyecto, es decir la desarticulación del equilibrio de atributos y búsqueda de efectos de sentido y apariencia o bien, como se cuestiona histórica o poshistóricamente la idea triatributiva del modelo vitruviano, aquél que otorgaba entidad al objeto arquitectural en tanto éste resolvía de manera armónica e integrada la triple exigencia de venustas/ firmitas /utilitas. bas podrían relacionarse en tanto operan sobre lo que genéricamente llamamos cultura histórica. Hemos postulado una caracterización de 12 modos históricos de proyecto que a la vez se presentan como pares dialécticos redefinidos de varias formas en torno del nietzcheano par apolíneo-dionisíaco, como comportamientos proyectuales que atraviesan la historia (fuera incluso de la comprobable datación histórica concreta de alguno de los modos, por ejemplo el modo ilustrado, que aludiría a la Ilustración del siglo XVIII pero que caracteriza una modalidad rastreable para atrás y para adelante en el decurso histórico) y comportamientos proyectuales que se verifican en diversas geoculturas, conscientes o no de la vigencia de tal noción fuera de su ámbito.

\begin{tabular}{l|c|c}
\hline \multicolumn{2}{l}{ ATRIBUTOS/MODOS } & \multicolumn{1}{c}{ MODOS HISTÓRICOS DE PROYECTO } \\
\hline NORMA-EXCEPCIÓN & LO CLÁSICO & LO BARROCO \\
\hline UTILIDAD-DESEO & LO TÉCNICO & LO ÚTOPICO \\
\hline CLASIFICACIÓN-MEZCLA & LO ILUSTRADO & LO HÍBRIDO \\
\hline NOVEDAD-RUPTURA & LO MODERNO & LO VANGUARDISTA \\
\hline MONUMENTO-PALIMPSESTO & LO AUTÓNOMO & LO HETERÓNOMO \\
\hline PAISAJE-MÁQUINA & LO NATURAL & LO ARTIFICIAL \\
\hline
\end{tabular}

Aquí se despliegan dos reflexiones historiográficas posibles: por una parte, la perspectiva de historizar un repertorio de modos en tanto cartografía de un conjunto determinado de comportamientos posibles a la hora de asumir subjetivamente un modo determinado de proyecto y por otra, de menor espesor histórico o mayor presentidad que imagina el modo como dispositivo subjetivo y táctico-relacional de proyecto en la situación socio-cultural contemporánea : una lleva a un criterio macrohistórico de modalización y otra a un criterio microhistórico pero am-
Por otra parte, en lo relacionado al criterio microhistórico de modalización ya referimos, con Buchanan al pasaje moderno/ posmoderno (en sus dos y sucesivas variantes deconstruccionista y ecologista) y con Guattari a la posibilidad de indagar sobre la relación entre enunciaciones objetivas (asimilables a mi concepto de lógica de proyecto) y ordenadas éticoestéticas o subjetivas (que se puede relacionar con mi noción de modos de proyecto, concebidos éstos en tanto una disposición pos-posmoderna relacionable con la crisis del capitalismo global 
y la emergencia del estatus de la multiculturalidad y por tanto, susceptible de referir a formas orbitales geosituadas de proyecto).

En la perspectiva microhistórica mencionada cabe situar otras características, diría de un presente-proyectual desprovisto de canonizaciones o referencias y vinculado si se quiere a procesos culturales que como los que Bourriaud indaga respecto del arte conceptual actual, avanzan en verbos o acciones de modalidad de proyecto como lo que se alude en los términos des-integrar o pos-producir y en general, en aceptar fragmentarismos y rupturas de la estabilidad / pregnancia / tectónica del artefactualismo urbano-arquitectónico.

Todo lo cuál desemboca en una instancia que recién nombramos como posvitruviana en tanto desarrollo de perspectivas de saberes y prácticas posproyectuales ligadas a cierta finalización o acabamiento del potencial tecno-anticipatorio del dispositivo proyectual como elemento para un ver-antes, transformado cognitivamente en prospección de tecnologías y funcionalidades y por tanto también en instrumento de verificación de efectos simbólicos de lo técnico y de la anticipación de soluciones utópicas.

La recaída del pro-yecto como u-utopía articula el ver-antes con el no-lugar y lleva el proyecto en esta fase histórica a servir de instrumento para predecir/proponer el lugar del no-lugar.

Pero quizá no sólo quepa la clásica referencia utópica al no-lugar (es decir, a una categoría espacial) sino asimismo al pro-yecto como prefiguración espacial de lo no ocurrido (aunque políticamente deseado) en el mundo social: el pro-yecto como concreción espacial de lo no ocurrido social, es decir, una vuelta relativa a la tradición fourieriana pero mas al servicio de planteamien- tos políticos: por ejemplo un pensar-proyectual del espacio no existente para formas sociales inéditas como la multitud o la reagrupación de sujetos en formas pos-familiares.

Y también el pro-yecto como eutopía, no sólo dar lugar (saturar el u-topos) sino tender al mejor lugar posible, es decir si cabe, introducir en el discurso utópico no sólo la respuesta a la necesidad que no tiene (solución de) lugar sino también al trabajo satisfactor de un estatuto del deseo.

La idea de los modos entronca con el tema de la relación entre historia y teoría como base para la conformación de una cultura proyectual, esto es una situación según la cuál el proyecto nunca es una operación de tabula rasa sino siempre una meditación reelaborativa sobre la experiencia proyectual que si bien es propia de cada sujeto-proyectista en su contexto de actuación a la vez es el grado de conciencia que dicho sujeto posee sobre la historia del proyecto.

De allí que este trabajo de pretensión teórica (en cierta manera enunciable como sistematizar el análisis del background teórico de la arquitectura contemporánea mas allá del fenómeno relativamente contingente de las lógicas, visibles ahora como las formas cognitivas que una mirada del tipo de los cultural studies habría permitido respecto de la arquitectura posmoderna) consiste en una selección de motivos o temas historiográficos en la perspectiva de montar un observatorio o laboratorio de análisis de la experiencia histórica de la arquitectura para ayudar a establecer lo que llamaríamos cultura proyectual del arquitecto.

Ese observatorio o laboratorio de experiencia histórica de la arquitectura se presenta en nuestro desarrollo, como tales 12 líneas (o 6 pares de nociones modales relativamente 
contrapuestas o dialécticas) que atraviesan por una parte. el tiempo histórico y por otra ayudan a comparar o analizar en sus aspectos relacionales, manifestaciones culturales distantes en lo neocultural, por ejemplo las relaciones pero también las confrontaciones entre Europa y América.

Es decir entonces que cada modo o noción de ese repertorio de 12 posturas podría ser descripto en su desarrollo histórico y también en su manifestación en diferentes campos geoculturales.

Usar algunas de esas categorías modales para revisar un linaje o genealogía histórica - por ejemplo, la larga duración del modo clásicotransforma la categoría de su condición histórica a una condición historiográfica o teórico-analítica y tal transformación sería lo que convierte la categoría en parte de la cultura proyectual o sea que la presenta no como rasgo histórico sino como argumentación activa o vigente.

Se trata así de pensar por ejemplo, un modo barroco que pueda reconstruir una historia larga desde un punto de vista de valor analítico-historiográfico de esa noción o condición específica y diferencial de proyectar mas allá de su precisa ubicación histórica: sería como pensar o identificar un comportamiento barroco antes o después de la existencia estrictamente histórica del barroco ${ }^{10}$.

10 En rigor esta manipulación teórico-historiográfica de una noción histórico-estilística precisa como es el llamado estilo barroco fue ya explorada fecundamente por Omar Calabrese en su La era neobarroca , Cátedra, Madrid, 1989.

Calabrese, si bien extrapola hacia delante el concepto barroco presentado como tal en el siglo XVII para postular formaciones discursivas modernas y contemporáneas que se oponen por asi decirlo al imaginario racionalista, instala la posibilidad metodológica de considerar un modo de proyecto como un repertorio de actuaciones
La intención de articular claramente historia y teoría (de la arquitectura y más específicamente del proyecto) implica situar la acción proyectual en el cruce de muchas líneas de fuerza -políticas, sociales, económicas, culturalesque son aquellas que el conocimiento histórico pone en evidencia, transparentando entonces por así decirlo, la trama de condiciones y determinaciones en que se sitúa genéricamente un proyecto y que hace que el mismo forme parte de la problemática general de:

- [1] mundos urbanos específicos (es decir determinados contextos socio-históricos, idea que va mucho más allá de los contextos entendidos como geometrías o morfologías urbanas o la mera condición agregativa arquitectura/ciudad percibida básicamente como cuestiones escalares),

- [2] los mundos propios de la cultura de la imagen (es decir, el campo que abarca puntualmente los temas y motivos de las artes plásticas en diversos y determinados momentos históricos) así como el campo que podemos denominar de los imaginarios sociales $\mathrm{y}$

- [3] los mundos propios de la cultura material con sus aspectos referidos a la cualidad técnica y valorativa de las cosas (es decir, como se producen éstas y como se consumen y se integran al circuito de intercambios y valores).

Los modos se pueden ver y operar como (relativas) invariancias históricas a saber, grandes

que podría verificarse en cualquier momento histórico no solo en tal sentido, futuro respecto del acuñamiento o invención de la noción sino también pasado o previo a esa invención. 
categorías historiográficamente analíticas; canteras o depósitos de experiencias encuadrables en una disposición diría, proactiva.

De todas formas, analizando la realidad de la experiencia histórica se ve que tales modos lejos de alcanzar una estrictéz canónica y operativa siempre están en trance de mutación y transformación, haciendo en definitiva que cada hecho proyectual puntual aun inscripto en tales marcos categoriales siempre tenga un aspecto fenomenológico específico, lejos de una mecánica reproducción

La crítica y analista de arte y literatura Graciela Speranza dice lo siguiente en el prólogo de uno de sus últimos libros ${ }^{11}$ : La distancia,

11 Graciela Speranza, Atlas portátil de America Latina. Arte y ficciones errantes, Anagrama, Buenos Aires, 2012, pp. 16-7. Este libro se acoge al modus de los proyectos taxonomistas y clasificatorios abierto-combinatorios inaugurado por Warburg en su Atlas Mnemosyne o Benjamin en su Libro de los Pasajes y teorizado por Buchloh, Guasch y Didi-Huberman, repertorizando un conjunto disperso y mutable de referencias a productosprocesos de arte y escritura en América Latina, en un formato clasificatorio pero a la vez con posibilidades de permutación y combinatoria.

Ese método al que adscribo fue descripto, aplicado a Warburg, de esta forma por nuestra autora: Warburg empezó a componer su serie inacabada de paneles móviles de láminas montadas sobre fondos negros y luego fotografiadas, en las que esperaba exponer el conglomerado de relaciones que observaba en las imágenes, las migraciones de formas, motivos y gestos que atravesaban fronteras políticas y disciplinares desde la Antigüedad hasta el Renacimiento e incluso hasta el presente. (p.14). Warburg concibió su Atlas como un combate contra la clausura del nacionalismo cultural exacerbado por la guerra y la asfixia de la ortodoxia dogmática. En un rapto después de la locura se le reveló una forma del pensamiento por imágenes, cuadros proliferantes de constelaciones permutables (para un maníaco no hay nada definitivo) en los que fluyen las polaridades, las antinomias, las supervivencias fantasmales de otros tiempos que anidan en las imágenes. Para desplegar esas discontinuidades del tiempo y la memoria hacía falta una "mesa de encuentros", un dispositivo nuevo de colección y exhibición que no se fundara en la ordenación racional ni en el caos de la miscelánea y un principio capaz de descomponer y recom- que no necesariamente es distancia física, mueve a interiorizar lo propio y matizarlo con lo ajeno, vuelve la identidad más oblicua, menos enfática, con una mirada extrañada que inspira la creación de mezclas, espacios discontinuos o sintéticos, lenguas impuras o depuradas, formas lábiles que no derivan de la negación del origen sino de una apertura vital y poética de las relaciones, ajena al nomadismo mercantilizado o turístico y el multiculturalismo adocenado.

En tal sentido si la noción de lógica pudiera asociarse a las formas predominantes de darle marco teórico al hacer arquitectónico de la cultura posmoderna -incluso demarcando una relativamente clara postura de negar los procedimientos modernos, al menos en lo metodológico sino en lo estético- el enfoque que ahora querríamos aplicar con la noción de modo habla de una recuperación de la base epistemológica del proyecto por así decirlo, dentro de una larga duración histórica que incluye sobre todo la consideración de una modernidad extendida (siglo XV o XVI en adelante) y también en definitiva, aquella historia presentificable o sea, entendible como la de experiencias que todavía tienen algún grado de contemporaneidad.

poner el orden del mundo en "planos de pensamiento" para que así dispuesto y recompuesto recuperara su extrañeza. Eso es el Atlas Mnemosyne, una "forma de conocimiento por montaje" (p.15). 